\title{
Our Missing Teachers
}

John Ewing (Math for America, New York, USA)

It was another amiable conference, scheduled over two days in a hotel that adjoined the campus of a large university. The topic was mathematics education, from elementary through to high school. The roughly 30 speakers were almost all people I knew well, some for many years. They were distinguished mathematics or education faculty from universities across the United States, with a few from Europe and Asia. Their talks and panels covered many topics from curriculum to pedagogy, from elementary school to high school and from policy to practice. I had been looking forward to the event.

As I settled into my seat near the back of the room, I looked at the list of participants. One aspect of the conference was strikingly familiar - the speakers included not a single practising classroom teacher. Only one was on a panel and that was because he was connected to a university teacher training programme.

Something similar happens at most conferences and workshops on K-12 mathematics education held in the United States (and many, although not all, other countries). The speakers are university faculty, education reformers, superintendents of districts, CEOs of corporations, even politicians - almost anyone other than practising teachers, the people who carry out the day-to-day work of K-12 education. When a handful of teachers are included, it's because they have some other role.

I have spent most of my life in or associated to universities. For most of that time, I never saw anything unusual about the missing classroom teachers. I worried regularly that research mathematicians were often missing from education events and projects. Reforming K-12 education should be a partnership between mathematics education and mathematics faculty, I insisted. Education policy disconnected from content loses its way, giving rise to "school mathematics" rather than "mathematics." But I never thought that failing to involve classroom teachers might be a problem.

\section{The problem}

The missing classroom teachers are a problem, of course, and for the same reason that missing mathematicians are. Talking about education, either policy or practice, without actual practitioners is just as nutty as talking about education without experts in content. It's easy to lose perspective, to misunderstand the consequences of actions and to misjudge the difficulty of success. Why leave out people who can provide such perspective?

But the absence of classroom teachers is a symptom of a more serious problem: we omit teachers because we do not think of teachers as professionals - masters of a discipline with special expertise and craft. We don't think of them in the same way we think of, say, medical doctors, engineers, or university mathematicians. Indeed, we don't think of teaching as a profession in the way we think about other professions. The public often sees classroom teachers as workers who follow instructions provided by someone else - the real experts. Teachers are like education contractors, not education architects. And because we don't think of them as professionals, we don't treat them that way.

At this point, some readers will be shaking their heads. "Not all classroom teachers are professionals," they protest. Of course, they are right, some are not. There are a great variety of classroom teachers. In many countries, including the United States, most teachers in lower grades are generalists, with little specialised training in mathematics. While they may be professional teachers, they are hardly professional mathematics teachers (or professional $X$ teachers for any value of $X$ ). How can they contribute to policy discussions about mathematics education? Teachers in the upper grades vary as well. Some have only modest backgrounds in mathematics and often teach routine courses in routine ways. Some have lost their edge over the years and become dull. Some may be knowledgeable in their subject but awful in their craft, unable to unpack ideas that are familiar to them. Some may be truly dreadful. Yes, yes, yes.

But some mathematics teachers are professionals. In the lower grades, they know their subject in surprisingly deep ways and are, in every respect, teachers of mathematics, inspiring young students. In upper grades, they are not only teachers of mathematics but mathematicians as well, with both insight and devotion to their subject. They are experts in their craft. They inspire their students. They guide and mentor their colleagues. They continue to learn, both mathematics and pedagogy, throughout their careers. These teachers have all these characteristics and they are professionals in every sense of the word. They deserve to be treated accordingly. When we treat them otherwise, we send a message that their professionalism isn't valued.

If we don't value our most accomplished teachers, they will not stay in teaching. If we don't treat them as professionals, the profession itself becomes unattractive and we will lose future accomplished teachers as well. If we want more high-quality teachers, we had better value the ones we have.

\section{A secondary problem}

This situation illustrates a second problem in education. When we look at teachers, we almost always focus on the weakest - the ones who are deficient in some way, who need repair, who represent some failure. It is hard to think of teachers as professionals who can contribute to education more broadly because we are focused on that awful algebra teacher who barely knew mathemat- 
ics and ruined mathematics for our son or daughter. We may remember a few great teachers in our own lives but when we talk about education, we think about the teachers who are deficient and need repair.

This is an unconscious theme in modern K-12 education. Reform has become a simple formula: find what's broken and fix it. Find the weakest teachers, the poorest schools, the most troubled students. Expose them, repair them, get rid of them and education will get better. This is educational reform today.

But it's a remarkably short-sighted view, strangely peculiar to K-12 education. In the business world, one doesn't only focus on what doesn't work well. To build a thriving business, you fix things to be sure, but you also find things that already work well. You build great businesses on those things, using them as the cornerstones. Similarly, a university president would never arrive on campus and immediately focus on faculty who are weakest. Great universities get built using the most prestigious and accomplished. Why do we try to improve education by focusing only on the rubble of failure? In life, excellence is built on excellence. Education is no different.

\section{Math for America}

Math for America ( $\mathrm{MfA}$ ) sets out to address these problems. The idea is embarrassingly simple - find genuinely accomplished teachers, give them opportunities modelled on professional life in universities, and trust them to take advantage of the opportunities. In short, find teachers who deserve to be treated as professionals and treat them that way.

("Math for America" is a misnomer in two ways. The programme includes science teachers as well as mathematics, in roughly equal numbers. Also, it is only for teachers in New York City rather than all America.)

MfA offers a 4-year master teacher fellowship for experienced mathematics and science teachers who are currently in the classroom (and who continue to teach). Teachers apply, are selected, and join a community of maths and science teachers spanning all the grades, although predominantly in grades 6-12. The community tries to model scholarly life in a vibrant university - workshops, seminars and lectures, covering maths or science, policy or pedagogy and abstract or practical topics. It also offers the opportunity to exchange ideas and informa-

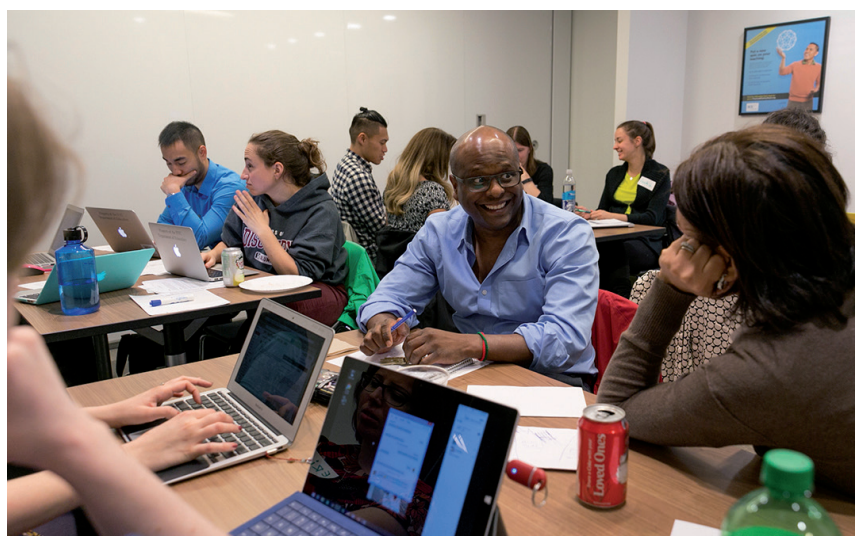

Typical evening at MfA. tion with colleagues from a wide range of schools. Fellows participate actively and enthusiastically in ways that suit their individual professional needs. They also receive an annual stipend (currently US $\$ 15,000$ ), which is meant to recognise their achievement and to compensate for their substantial commitment. Teachers can also apply to renew their fellowship.

New York City's school system is large: 1.2 million students in 1800 schools taught by about 75,000 teachers. MfA now has over 1000 teachers - about $10 \%$ of the maths and science teachers in the city. Is that the right percentage? Perhaps. It seems about right in New York City. The larger the number, the greater the effect, of course. On the other hand, it is essential to have accomplished teachers to make this programme work. In New York, $10 \%$ seems to strike the right balance.

While the basic idea is simple, the details are more complicated. They are important! It would be easy to allow a programme like this to drift into something resembling traditional education reform, for example, by selecting teachers who were not accomplished or by converting the workshops into "teacher repair". The lure of traditional reform is powerful and one must safeguard against it. Here are some details:

\section{Selection}

The selection process is important because $\mathrm{M} f \mathrm{~A}$ 's success depends upon finding accomplished teachers. Selection begins with a lengthy application consisting of information about a teacher's education (including transcripts) and career. Applicants submit a short essay and a lesson study. They have three people write detailed letters of recommendation. They take a standard (undemanding) test of content that is specific to their specific discipline. One element is notably and deliberately missing from the selection process - test scores from a teacher's students. The application is structured in a way that helps teachers decide whether the fellowship is right for them and encourages them to stop if it's not. We don't encourage applications simply so we can brag about our low acceptance rates.

Applicants who make it through the first part of the process are invited for an interview. At that interview, they are first assigned to work in small groups, creating and presenting a piece of mathematics or science they

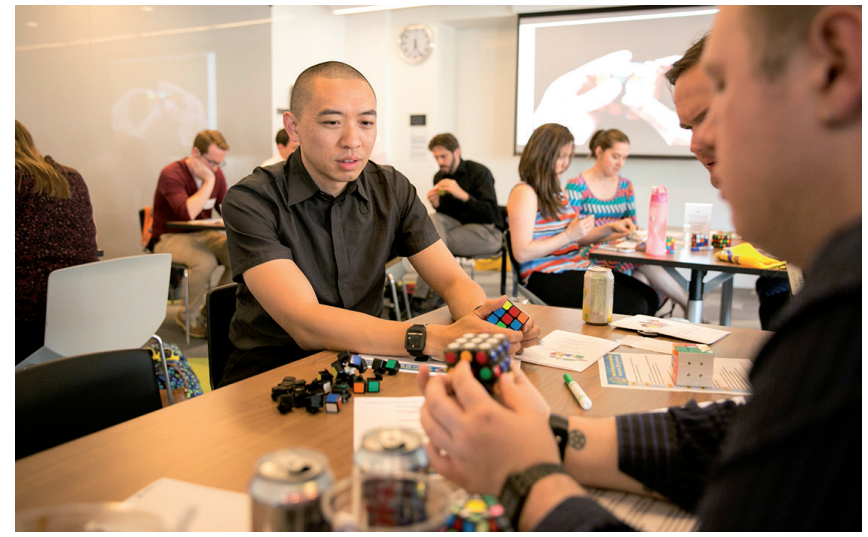

An MfA workshop on puzzles. 
can choose themselves (because it's interesting and not because they teach it). Afterwards, they converse about the presentations, asking each other questions, answering them and offering observations. A three-person team (a mathematician, an educator and an $\mathrm{M} f \mathrm{~A}$ representative) observe all this. The team then interviews each candidate separately, following up on what's been observed. The process allows us to gauge with remarkable accuracy a teacher's mathematical or scientific knowledge, their ability to communicate that knowledge and their approach to collaborative work. At the end, we know each candidate's strengths and weaknesses.

Final acceptance is carried out by $\mathrm{M} f \mathrm{~A}$ staff, using the complete dossier for each applicant and a set of carefully developed rubrics, along with sound judgment.

\section{Scholarship}

During most evenings, the $\mathrm{M} f \mathrm{~A}$ teachers swarm throughout our New York City offices, which include a lounge, a small library and a number of seminar rooms and breakout areas. This is meant to approximate the facilities of a high-quality maths or science department.

Some might describe what $\mathrm{M} f \mathrm{~A}$ teachers do during these evenings as "professional development". I avoid that term. Traditional professional development is often dull and dreary, disconnected from a teacher's discipline, and aimed at fixing deficiencies or providing tips on how to improve test scores. MfA's workshops, seminars and mini-courses are meant to be intellectually engaging. Some are directly connected to instruction, but many are about maths or science - a recent research result or an interesting topic - or about education challenges and policies. A few are single sessions but most are given in sequences of three or more sessions. In the 2017-18 academic year, MfA offered over 400 "courses" like this, taking place in nearly 1000 sessions.

Here is the most important part: two-thirds of these courses are created and led by the teachers themselves. $\mathrm{M} f \mathrm{~A}$ provides the infrastructure. We put together the catalogue, determine the schedules and provide the facilities, but the teachers themselves drive most of this forward - in the same way that faculty and students drive seminars and colloquia in a healthy university.

Of course, some workshops are run by people from the outside, including mathematicians, scientists and educators. But even these workshops are inspired by teacher interest and aimed at intriguing, rather than fixing, teachers.

For many teachers, especially those in small schools with few colleagues in their field, MfA's scholarly community serves as their essential connection to their discipline. It makes them feel like mathematicians and scientists. It makes them feel professional.

\section{Interaction}

Teaching is a lonely job. People are sometimes surprised when I say this. They picture teachers surrounded by dozens of students and they wonder how anyone can be lonely with all those students. But teachers interact professionally with teachers and the modern structure of

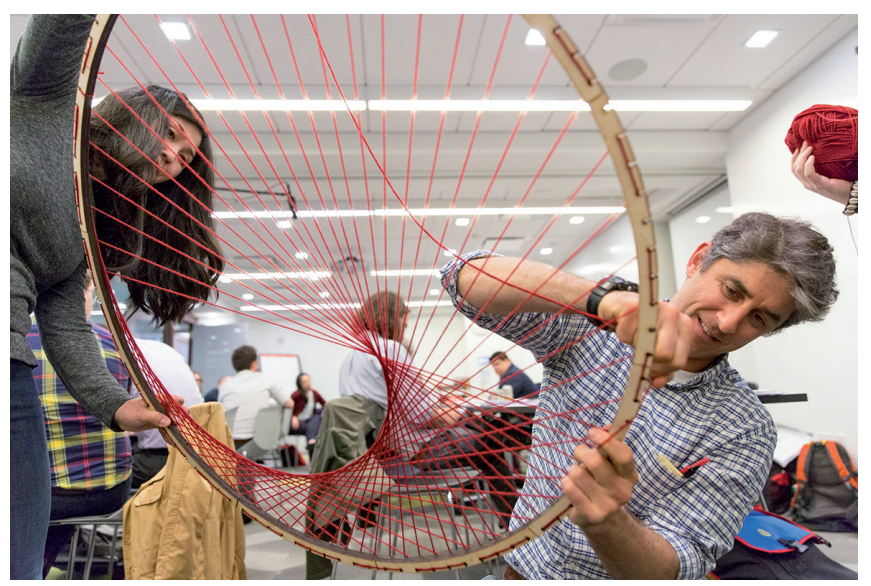

Old fashioned string art.

schools makes these professional interactions more and more difficult.

One of the benefits of the MfA community is the opportunity to interact with other teachers in new ways: mathematics teachers talk to science teachers; middle school and elementary teachers talk to high school teachers; and teachers at exclusive schools (in NYC they are called "exam schools") talk to those enrolling mainly high-needs students. They all come together. This kind of professional interaction builds connections, which creates networks that teachers can draw on for years to come. It is a kind of interaction that seldom happens in the everyday lives of teachers. At MfA, it happens naturally.

We also foster such interaction. Part of our programme (about 15\%) consists of teachers who are in the first few years of their teaching careers. We pair them with master teachers who serve as mentors, not merely in name but in fact. Both junior and senior teachers profit from these relationships. Many of our workshops are offered in a special format - Professional Learning Teams (PLTs) - that bring together 15-20 teachers over the course of a semester or year. PLTs are always coled by a pair of teachers and adhere to a special format designed to involve all participants in the ongoing discussions. We even run workshops on how to run workshops, inside and outside of $\mathrm{M} f \mathrm{~A}$. We encourage $\mathrm{M} f \mathrm{~A}$ teachers to start their own PLTs in their schools.

University mathematicians are often unaware that such routine interaction with their colleagues plays an essential role in their professional lives. It is an unremarkable part of life in a good university. For classroom teachers, these interactions are a new experience that change the way that teaching feels.

\section{Trust}

None of this works without one final ingredient: trust. $\mathrm{M} f \mathrm{~A}$ fellows are required to participate in a modest number of workshops, roughly one session per month. (Most participate in far more!) We don't require them to learn any particular content. We don't ask them to acquire any particular skills. We are not fixing any particular deficiency. We trust them to decide for themselves how they want to grow professionally. 


\section{Sample Mathematics Workshops Spring 2018}

Applying Ideas from Modern Algebra to Secondary Teaching (MINI)

Combinatorial Game Theory $(S S W)$

Delving Deeper into Fraction Subconstructs and Processes (PLT)

Dynamic Lesson Planning Using Geometer's Sketchpad $(S S W)$

Exploring Rational Tangles $(S S W)$

Fostering a Growth Mindset in Mathematics (PLT)

How to explain hard "Why" questions in Algebra and Geometry using Calculus (MINI)

Introduction to Category Theory (MINI)

Investigating Calculus Teaching and Learning $(P L T)$

Islamic Art and Geometry (MINI)

The Mathematics of Gerrymandering (MINI)

Multi-criteria Decision Analysis for High School $(S S W)$

Made You Look - Statistics through Data

Visualizations $(T T)$

Using Mathematical "Magic" to Engage Students in Mathematics (MINI)

Vertical Alignment in High School Math $(I G)$

Similarly, we invite teachers to submit proposals for workshops and courses based on their own ideas and not ours. We vet these proposals, of course, but we trust the teachers to come up with good ideas. And they do!

Trust is a crucial ingredient in changing the way we think about teachers. It is often confused with education laissez faire - the proposition that teachers should do whatever strikes their fancy in the classroom. But laissez faire is impractical in most settings (including, it should be added, in universities!). Professional trust is different and more subtle. It means trusting teachers to control their own professional lives, deciding what's most important to them and how they want to develop their own careers. Extending that trust is important.

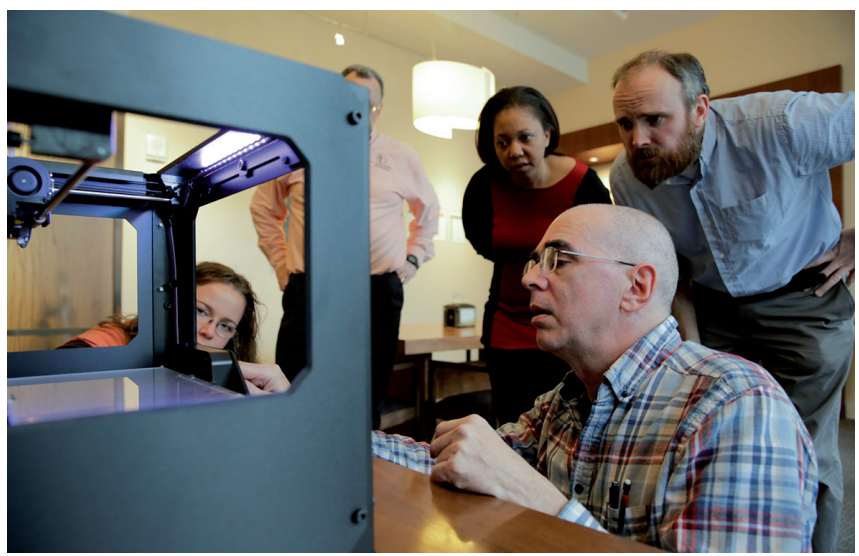

A 3D printer in the $\mathrm{MfA}$ lounge.
For many of our teachers, this is their first experience with this kind of trust. Teachers' careers often progress from one mandated professional development experience to the next, many of them useless and some of them dreadful. They hear public figures proclaim how much they "respect" teachers, without extending even a modicum of trust in this sense. They are controlled, regimented and evaluated by a system designed with the least able teachers in mind. $\mathrm{M} f \mathrm{~A}$ tries to change that, at least in one part of their professional lives. It is an important change.

One aspect of $\mathrm{MfA}$ is not as essential as the previous four but still deserves a mention. Master teachers can renew their fellowship after four years.

Renewals are not automatic. They require both an application and an interview (each different in nature from the initial ones). We expect more from master teachers when they renew. They are meant to be leaders, contributing more to $\mathrm{M} f \mathrm{~A}$, their colleagues and (possibly) their own schools. We make this a requirement but not an overbearing one. The renewal itself depends on our assessment of a teacher's ability to take on this role. Not all master teachers choose to renew and not all who apply are accepted.

If we did not permit renewals, we could offer fellowships to more teachers. But we would lose part of what makes $\mathrm{M} f \mathrm{~A}$ thrive. The senior master teachers who stay on for two or more fellowships play a special role in our community. They mentor those who are new to MfA: They take the lead in proposing workshops and running them. They model what an active professional life looks like; and they often carry their $\mathrm{M} f \mathrm{~A}$ experience outside to their schools and to the rest of public education.

While renewals may not be essential, they make $\mathrm{M} f \mathrm{~A}$ more effective.

\section{Advocating}

$\mathrm{M} f \mathrm{~A}$ has evolved over time. The original programme was conceived by Jim Simons and a group of financial mathematicians in 2004. The original implementation created a fellowship that enticed mathematically talented individuals to become teachers - a year of training, four years of commitment, substantial stipends, and a community. The programme was supported by an annual poker benefit together with the Simons Foundation.

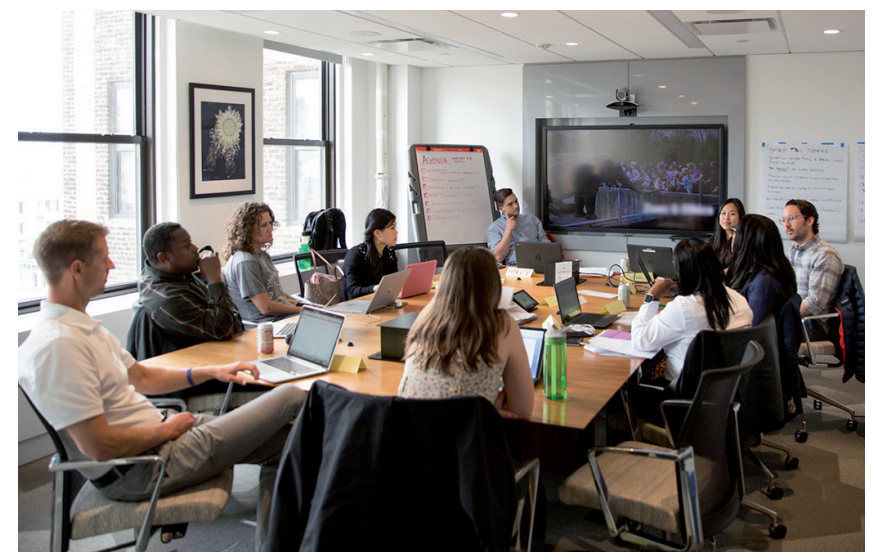

A Professional Learning Team (PLT). 


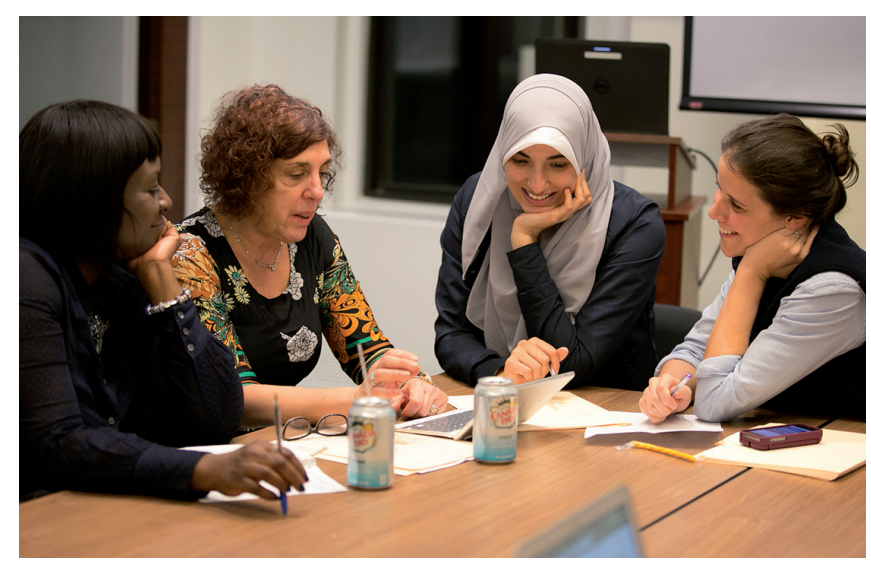

MfA teachers in a breakout.

Gradually, MfA discovered that many highly accomplished mathematics teachers were already in classrooms. Many of them were leaving and keeping them seemed more efficient than creating brand new teachers. The master teacher programme began to grow in 2012. A similar programme was created for teachers early in their careers. Science was added to broaden the appeal. The scope was extended to include maths and science elementary teachers. Now, after 14 years of evolution, MfA has slightly more than 1000 teachers in its fellowships - about $10 \%$ of the maths and science teachers in New York City. About half are in maths and half are in science. Most are master teachers and some are early career. Watching them work together each evening is inspirational.

$\mathrm{M} f \mathrm{~A}$ in New York City could serve as a model for other programmes elsewhere. We have tried to persuade others to create similar programmes in other locations with limited success. A few arose in other cities in the U.S., with the largest in Los Angeles (nearly 100 teachers). A large, publicly-funded programme began several years ago in the rest of New York State (which has roughly the same population as New York City). It currently has over 900 teachers at nine sites around the state. We are working with other states to help them create similar publicly-funded programmes, not identical but similar to MfA.

Advocating is a tough job, however. People sympathise with the goal but the approach can be jarring. That we focus on excellent teachers seems counter-intuitive to many people, especially education reformers. Why waste resources on teachers who are already accomplished? Why not concentrate on teachers who need help? And many people find it hard to trust teachers in this way. They can only remember that dreadful teacher they (or their child) recently encountered at school. Surely that teacher doesn't deserve a stipend or our trust!

If we really want to improve the quality of mathematics and science teachers, however, we need to find a way to overcome these obstacles.

\section{Coda}

Does MfA work? It's too early to tell for sure. Unlike traditional education reform, $\mathrm{M} f \mathrm{~A}$ is not about fixing teachers. There is no "treatment" that can be withheld from a control group to see whether the dosage is correct. There is no simple statistic that measures what we want to achieve. Some things are hard to measure with numbers. Professionalism is one of them.

In two respects, though, $\mathrm{MfA}$ is already successful:

- In the U.S. today, experienced teachers leave teaching for other careers at an alarming rate (about $8 \%$ each year). $\mathrm{M} f \mathrm{~A}$ teachers leave at a far lower rate (3\%). We want experienced, accomplished teachers to stay in teaching even if it is only for four additional years.

- Throughout the world, teachers complain frequently about shallow and useless professional development. Teacher-led professional development that treats teachers as professionals is a welcome change. $\mathrm{M} f \mathrm{~A}$ teachers thrive in such an environment. Even the most accomplished teacher wants to grow professionally and in $\mathrm{M} f \mathrm{~A}$ they do.

But the ultimate goal is to change perceptions - to convince the public and teachers themselves that teaching is not merely standing in front of a classroom and that it is a profession requiring mastery of content and craft, which takes place over many years and is motivated by curiosity, ambition and pride. Teaching is not preparing students for tests. It is not following instructions. It is not reciting facts or procedures. It is a profession and we should welcome its accomplished professionals into the mathematics community ... and treat them like the professionals they are.

Perceptions only change over time, however. Achieving this goal will require persistence and patience - qualities that are frequently missing from educational reform today. Fortunately, $\mathrm{MfA}$ has both.

(For more details and background, see the Math for America website at www.mathforamerica.org.)

All photo credits: Michael Lisnet, MfA photographer.

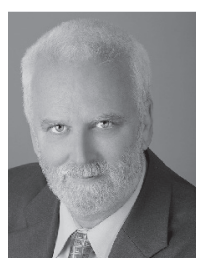

John Ewing is the President of Math for America, an organisation associated to and supported by the Simons Foundation in New York City. He was formerly the Executive Director of the American Mathematical Society and, before that, he was on the faculty of Indiana University. Since joining $M f A$ in 2009, he has gained both humility about the difficulty of mathematics education and certainty that improving it requires us all to work together - mathematicians, maths educators and classroom teachers - as equal partners. 